\title{
Charting the history of agricultural experiments
}

\author{
Giuditta Parolini ${ }^{1,2}$
}

Received: 30 April 2015/Accepted: 29 June 2015/Published online: 24 July 2015

(C) Springer International Publishing AG 2015

\begin{abstract}
Agricultural experimentation is a world in constant evolution, spanning multiple scientific domains and affecting society at large. Even though the questions underpinning agricultural experiments remain largely the same, the instruments and practices for answering them have changed constantly during the twentieth century with the advent of new disciplines like molecular biology, genomics, statistics, and computing. Charting this evolving reality requires a mapping of the affinities and antinomies at work within the realm of agricultural research, and a consideration of the practices, tools and social and political structures in which agricultural experiments are grounded. Three main questions will be addressed to provide an overview of the complex world of agricultural research investigated by the special issue: What is an agricultural experiment? Who is an experimenter in agriculture? Where do agricultural experiments take place? It will become apparent that agricultural experiments have a wide relevance for human development as they touch upon concerns related to human health and nutrition, contribute to policy discussions, and can affect the social and political structures in which farming is embedded.
\end{abstract}

Keywords Agriculture - Experiment - Field science - Laboratory science · Farming

In his short story entitled "On Exactitude in Science", Jorge Louis Borges introduces the reader to a paradoxical form of cartography, "a Map of the Empire whose size was that of the Empire, and which coincided point for point with it". The

Giuditta Parolini

giudittaparolini@gmail.com

1 Technische Universität Berlin and Berliner Zentrum für Wissensgeschichte, Berlin, Germany

2 Institut für Philosophie, Literatur-, Wissenschafts- und Technikgeschichte, Technische Universität Berlin, Sekretariat H23, Straße des 17. Juni, 135, 10623 Berlin, Germany 
1:1 map proved a virtuoso exercise, but posterity had no use for it and the map was left to the inclemency of the weather that reduced it to "tattered Ruins", "inhabited by Animals and Beggars" (Borges 1998, p. 325). Borges' fictional account has a valuable moral for this special issue that aims at charting the vast, uneven and (in some areas) largely unexplored terrain of experimentation in twentieth-century agricultural science. Due to the astonishing multiplicity and diversity of the activities that can be subsumed under the heading 'agricultural experiment'-they are indeed an Empire of their own - it is tempting to reproduce the virtuoso exercise described by Borges and create a map that is a mimetic description rather than a representation.

However, this approach cannot be successful because agricultural experimentation is constantly evolving, spanning multiple scientific domains and affecting society at large. Representing it would rather require a series of maps reproducing at incremental times the development of agricultural experimentation and its impact on rural communities. In fact, even though the questions underpinning agricultural experiments remain largely the same, the instruments and practices for answering them have changed constantly during the twentieth century with the advent of new disciplines like molecular biology, genomics, statistics, and computing. Charting this evolving reality requires a mapping of the affinities and antinomies at work within the realm of agricultural research, and a consideration of the practices, tools and social and political structures in which agricultural experiments are grounded.

The papers in this special issue represent a first contribution-incomplete, but nonetheless representative-towards exploring the dynamic geography of agricultural experimentation. Combining historical and philosophical perspectives, they investigate through case studies some of the main issues arising in agricultural research. They deal with plant and animal experiments, touch upon basic science and agricultural practices, explore both laboratory research and field experimentation, and examine ethical and policy issues. The settings considered range from the National Institute of Agricultural Botany in Cambridge to the agricultural station of Rothamsted in Hertfordshire, from the Roslin Institute for animal biotechnology in Scotland to the South-West England areas that became the location for experimenting with badgers and bovine TB. A commentary by Jonathan Harwood, included in the Notes and Comments section of this issue, reflects on the main points raised in the examination of the case studies. In this introductory essay three main questions will be addressed: What is an agricultural experiment? Who is an experimenter in agriculture? Where do agricultural experiments take place? The examination of these questions will provide an overview of the complex world of agricultural research investigated by the special issue.

\section{What is an agricultural experiment?}

According to Harro Maat the common features of experiments in agricultural science "are a treatment, a hypothesized process or causal mechanisms to be tested". Each branch of agricultural science "will have its manual or guidelines for experimentation depending on the objects of the experiment, the place where the 
experiment is done, the treatment or process that is tested and the methods used" (Maat 2011, p. 187). ${ }^{1}$ Yet, this definition makes us none the wiser about who counts as an experimenter and what counts in practice as an experiment in agricultural science, echoing Peter Galison's investigation of the material culture and experimental practices of twentieth-century microphysics in Image and Logic (Galison 1997, p. 2). ${ }^{2}$ Nor can Maat's definition really answer the question of "how experiment and knowledge (sic) relate" (Steinle 2002, p. 409) in agricultural research, especially considering that the very notion of knowledge in agricultural science remains contested between results of value for fundamental research and results of practical applicability. Furthermore, as argued by Astrid Schwarz, during the twentieth century the "idea of experimentation has come to be associated empathetically with the notion of the so-called knowledge societies" and "experimentation is currently a dominant mode of experiencing, describing and designing cultural as well as natural environments" (Schwarz 2014, p. 1). This change is particularly significant for the investigation of agricultural experiments, because many experimental activities connected with agriculture have an immediate impact on society, for instance in the case of GM crop field trials (Bonneuil et al. 2008).

Since the 1980s philosophers and historians have taken an interest in scientific experimentation that has gone beyond theory-dominated accounts. Attention has been paid even to the material aspects of experimentation, including scientific practices and instrumentation (e.g. Hacking 1983; Galison 1997). At the same time the role of the experiment as hypothesis-testing device has been complemented by more complex epistemological accounts that include the possibility of "exploratory experimentation" (Burian 1997; Steinle 2002, p. 419), a perspective that in recent years has also paved the way to data-driven science (Leonelli 2012; Schwarz 2014, pp. 70-71). As argued by Richard Burian, exploratory experiments allow access to experimental entities "in ways that do not depend wholly on the specific disciplinary or theoretical background of the experimenters who initiated the work on those objects" (Burian 1997, p. 45). They are therefore frequently encountered in the life sciences, where experimental research often transcends disciplinary boundaries. Epistemologies of experiments based on exploratory work (e.g. Rheinberger 1997) have offered a more suitable framework for examining the research done in the soft sciences, in particular biology. They have provided a valuable alternative to the histories and philosophies of experimentation centred on the exact sciences, which for a long time formed the general model for scientific research.

\footnotetext{
${ }^{1}$ Maat's definition is the result of the statistical approach to agriculture: research problems are discussed in terms of treatments and their application. However, this is hardly the language that farmers would use to describe their experimental work. Nor is justice done in this definition to the merely observational activities that are part of agricultural research.

${ }^{2}$ In Galison's account the categories of experiment and experimenter are "defined, dismantled, and reassembled", starting from the material culture of the detectors used in microphysics and the associated data collecting practices (Galison 1997, p. 7). Similarly, the case studies presented in this special issue take into account materialities and scientific practices to tackle the evolving concept of experimentation in twentieth-century agricultural research.
} 
According to this new perspective, the places where experimentation is done have also grown more numerous. While standard accounts identified a single site for experimental activity, the laboratory, the study of the soft sciences needs to take into account also field science (Kohler 2002). Overtly enthusiastic supporters of experimentation claim that "nowadays, experiments are happening everywhere and they might be conducted by just about anybody", that they do not end with the scientific enterprise, but are a common concern of the social and political sciences, and that they impact on the ideal of engagement and social participation (Schwarz 2014 , p. 1). These broader categories and ideas of experimentation established in the past few decades are certainly essential to a full account of agricultural experimentation, but this more flexible approach does not in itself solve all of the difficulties. Two obstacles remain.

The first is the paucity of interest that the whole history of twentieth-century agricultural science (including horticulture) has so far received (Harwood 2005, pp. 26-28), although there is evidence that this situation is slowly changing (Harwood 2006; Phillips and Kingsland 2015). The scarcity of sources on agriculture is a hindrance towards charting a history of agricultural experimentation. Certain branches_-plant breeding, for instance (Kloppenburg 1988; Palladino 1993, 1994; Müller-Wille 2005; Bonneuil 2006; Wieland 2006; Saraiva 2010; Charnley 2011; Harwood 2012)- have received more attention than others, but much more work is required in order to survey agricultural research as a whole. Moreover, the extensive nature of agricultural science is not defined only by the number of branches it includes, but also by its worldwide diffusion, and knowledge of localised practices and regional variations is essential in any definition of experimental work in agriculture. Therefore, a global history of agricultural research needs to consider and represent national traditions alongside general principles.

The second obstacle in charting the history of agricultural experiments can be identified in its scope: agricultural experiments span both the plant and the animal kingdoms, and the world of farming practices using a variety of instruments. The task would, therefore, require an encyclopaedic knowledge. Unlike the nineteenth century, when agricultural research resorted mainly to the tools of chemistry (Brassley 1995), since the beginning of the twentieth century the proliferation of the branches of agricultural science has reshaped the discipline and its experimental criteria. Molecular biology has offered the opportunity to sequence the DNA of plants and animals, biotechnologies have made possible complex manipulations of the genome, and computing and information technologies have provided instruments for storing and sharing data. These data are in turn used for modelling, amongst other things, crop growth or the impact of crops on the ecosystem.

Further difficulties in charting the history of agricultural experiments are rooted in the ambiguous definition of agricultural science itself (Brassley 1995, p. 467). Cross-contaminations with agricultural education and extension work on the one hand, and with farming practices and food processing on the other, make this definition problematic. While mapping agricultural experiments, the experimental activities undertaken by farmers and farming organisations (e.g. Richards 1989), or the engagement of the food industry with science and technology (e.g. Atkins 2000), cannot be ignored. Denise Phillips and Sharon Kingsland, in particular, invite us to 
"reexamine and take seriously the intimate connection between scientific development and the practical goals of managing and improving-perhaps even recreating-the living world to serve human ends" (Phillips and Kingsland 2015).

This is especially relevant to the history of agricultural experimentation and its impact on farming, as discussed by James Scott (1998, chap. 8). According to Scott, the Green Revolutions of the twentieth century failed to export high-modernist agriculture-based on monoculture, mechanisation, intensive use of fertilizers, yield maximisation-into tropical and subtropical areas, because Western scientific experts relied mostly on the results of scientific experimentation carried out according to simplifying principles. They failed to recognise the limitation of these assumptions in different environmental and social contexts. In particular, Scott condemns as a fictional construction "the Everyman cultivator, who is interested only in realizing the greatest yields at the least cost" (Scott 1998, p. 299). Rather, traditional farmers in Africa, Asia and America can be viewed as "lifelong experimenters", able to adapt their lifestyle to complex and constantly changing environments and to develop farming practices suitable for their social and political structures (Scott 1998, p. 304).

Thus, there is no golden standard of agricultural experimentation, but many instruments, practices and experimental values are called upon, whenever appropriate. That being the case, there is no simple definition of agricultural experimentation, and general ideas have to be gathered from the examination in specific cases of how agricultural experiments are implemented and by whom.

\section{Who is an experimenter in agriculture?}

When Rothamsted Experimental Station, the oldest agricultural station in Britain, was founded in the 1840s, its scientific staff consisted of just one chemist, Joseph Gilbert, a former student of the German agricultural chemist Justus von Liebig, and some assistants. The agricultural institution was originally founded and sponsored by John Bennet Lawes, an English squire engaged in the fertilizer industry, and thus its research was mostly concerned with soils and fertilizers (Clarke 2004). For over half a century, under Gilbert's supervision, the experimental activity at Rothamsted was limited to the collection and chemical analysis of soil and yield samples obtained in the local field experiments. The station's experimental program, however, quickly developed at the turn of the century and by the early 1920s the institution was already employing bacteriologists, botanists, physicists, statisticians, crop ecologists, entomologists, and mycologists for its research activities (Rothamsted Experimental Station 1921, pp. 4-5).

The Rothamsted case is representative of a general trend in agricultural research at the beginning of the twentieth century. Agricultural science relinquished its privileged links with chemistry and opened its borders to new forms of scientific expertise. Around 1900 the newly born discipline of genetics began to enter into the world of agricultural research (Paul and Kimmelman 1988), but, as argued by Jonathan Harwood, the actual impact of Mendelism on breeding practices was "relatively modest" in the first half of the twentieth century (Harwood 2015, 
p. 364). Mendelism "provided a scientific explanation for breeding practice", "allowed breeders to reflect upon the adequacy of existing practices", and "served as a heuristic to open up the possibility of improved methods", but breeding hardly had revolutionary effects at that stage (Harwood 2015, p. 347). The institutions concerned with animal research, besides fostering expertise in animal breeding, also nurtured veterinary competences to control infections in livestock (Woods 2004).

During the early years of the twentieth century, agricultural scientists also developed an interest in food research. By the 1910s, Britain already had centres like the Reading-based National Institute for Research in Dairying, and the Rowett Research Institute in Aberdeen that worked on problems of food safety and nutrition (Cooke 1981). These two areas have since then become more and more relevant, extending further the list of experimental scientists engaged in agricultural research. Moreover, during the twentieth century, also agricultural extension services promoted their own experiments aimed at helping farmers in choosing the best methods of cultivation, crop varieties or fertilizer schemes. The National Agricultural Advisory Service, for instance, was established in England and Wales in 1946. It committed in its mission statement to "carry out such experiments and investigations as may be required to solve problems and to determine the local applicability of new discoveries and inventions, and to be the means of bringing to the attention of research workers problems that seem to call for fundamental investigations" (Rae 1955, p. 261). But the first experimenter in agriculture is the farmer, be it the affluent and educated member of the upper classes, like the English maltster Edwin Beaven, actively engaged in barley variety trials from the 1900s onwards (Palladino 1994), or the African farmer of the Mende tribe, willing to test the quality of seeds using nothing more than "[a] hundred or so grains and a fist full of moisture-retentive soil [...] wrapped up in a special leaf the size of a dinner plate" (Richards 1989, p. 19).

Experimenters in agricultural science can also be found among the R\&D staff working for agribusinesses. Two notable examples are provided by the brewing industry. The Danish Wilhelm Johannsen, for instance, first worked for, and then collaborated with, the Carlsberg Laboratory, a private research venue connected to the Carlsberg Brewery in Copenhagen. Johannsen's research on barley breeding for the Carlsberg Laboratory contributed to the development of his theory of pure lines (Müller-Wille 2007). Another agricultural experimenter actively engaged in the brewing industry was the chemist William Gosset, hired by the Guinness Brewery in Dublin at the turn of the twentieth century. Gosset was engaged in field experiments with barley varieties and in the interpretation of the experimental results gained at Guinness' experimental brewery, where samples of malt and hops were examined and their characteristics related to the quality of the beer produced (Gosset 1962, 15/09/1915). This experimental work prompted Gosset to develop his Student's $t$ distribution (1908), the first statistical tool developed ad hoc for the analysis of small samples, i.e. the limited sets of experimental data that are often encountered in agricultural and biological research (Fisher Box 1980).

Since then, statistical methods have become part and parcel of agricultural science, as described in this issue by Giuditta Parolini for the case of Rothamsted Experimental Station, and statistics is today presented as essential to "the 
intellectual equipment of a scientist working in agriculture or the experimental side of biology" (Mead et al. 2002, p. ix). Yet, despite the expectations that accompanied the emergence of statistics in agricultural science (and more generally in experimental research), statistical methods have not made the planning and analysis of agricultural experiments straightforward. In the first half of the twentieth century, for instance, randomisation generated controversies. Dominic Berry's contribution to this issue describes the case in relation to the field trials set up by the National Institute of Agricultural Botany in Cambridge. Even today, when best practices for the design of experiments are agreed upon, the experimental analysis that follows data collection can cause controversies. Whenever agricultural experiments concern problems of public relevance, the debate moves from the scientific level to the one of policy. In this sense even politicians and public health officials are part of the experimental life of agriculture, when they intervene to choose one among several options (Bonneuil et al. 2008).

During the first half of the twentieth century women were not well-represented in agricultural science. The women who did experiments in plant genetics at the John Innes Horticultural Institution (Richmond 2007), and the graduates of the Horticultural College, Swanley, who moved into scientific institutions (Opitz 2013), were exceptional in a male-dominated world. Often it was not a progressive attitude, but rather a scarcity of available funding that provided these women with a point of access into science: female scientific talent was, in fact, cheaper to hire and maintain. Women scientists and assistants in early twentieth-century Britain earned much less than their male colleagues (Opitz 2013, p. 59).

Who is then an experimenter in agriculture? The immediate answer is that there cannot be a single type of experimenter, as there is no single type of agricultural experiment. The people engaged in agricultural research belong to several categories, ranging from farmers and extension officers, to the R\&D staff of the food industry and the personnel of agricultural institutions. The differences among them are striking, their research agendas sometimes even clash, yet they have one thing in common: in the day-to-day interaction with their experimental objects, they cannot ignore the fact that agricultural science is a complex world where fundamental scientific problems and farming practices, policy and ethical issues all converge.

\section{Where do agricultural experiments take place?}

The geographer David Livingstone claims that scientific knowledge has spatial dimensions. No matter how much science presents itself "as some transcendent entity that bears no trace of the parochial and the contingent", it remains "a human enterprise situated in time and space" (Livingstone 2003, p. 13). A geographers' insight is particularly relevant in charting the history of agricultural experiments because, in many of the relevant sites of agricultural research, the 'local' is an irreducible factor. Even if the overall aim of agricultural science is to produce global knowledge, it is not very helpful to experiment with tropical crops in temperate regions, nor possible to assume that a fertilizer will have the same effect 
on every type of soil, nor again can new plant varieties and animal breeds be selected without considering the native ones, if results sustainable for the environment are to be achieved. Many more examples can be added in support of the situatedness of agricultural experiments and the necessity to account for it.

The geography of agricultural experiments can be tackled at two levels. On the one hand the 'place' is the physical location where experimental work is performed, such as the field or the laboratory, the archive and the horticultural garden. On the other hand the 'place' is also the institutional context-an experimental station or other scientific institution, an extension service, a commercial farm, a business company, etc.-where agricultural experiments take place. Often, agricultural institutions rely on substations for their experimental work. Moreover, they also cooperate with other scientific institutions and with commercial enterprises (farms, food producers, etc.), sharing experimental facilities, knowledge and, sometimes, even patents. These geographic, social and economic networks define the space where agricultural experiments are performed. Place matters, therefore, in agricultural experimentation in terms of the opportunities and constraints for research: field experiments on farmers' land, for instance, have been used to introduce new agricultural practices among Californian farmers (Henke 2000), while the Mendelian hybridisation experiments conducted by the botanist Nils Herman Nilsson-Ehle at the Swedish station of Svalöf found an epistemological obstacle in the recording procedures long-established in the institution (MüllerWille 2005).

Field and laboratory are the two main locations for agricultural experiments, but by no means they are the only ones worth investigating. The archive must also be regarded as a key site of agricultural experimentation. One example is the crop, sample and data archive that offers information on the long-term experiments started at Rothamsted Experimental Station in the nineteenth century. Another example are the seed banks envisioned nowadays both as repositories of biodiversity and an opportunity for a truly global plant research. Furthermore, several hybrid realities exist between the field and the laboratory, such as the field laboratory, the glasshouse or the experimental garden. Finally, in recent decades the very organisms under investigation by agricultural research have themselves become the sites of experimental activity, as highlighted in this issue by Miguel Garcia-Sancho's paper on Dolly the sheep. Another example is the plant Arabidopsis thaliana that is now one of the most successful model organisms for plant genetics (Leonelli 2007).

The physical space in which agricultural trials are carried out is mutually related to the institutional space that provides the context for experimentation, as exemplified by field trials. While farmers experiment on their own farmland as they find it, experimental scientists require an adjustment of the wilderness of the field, before it becomes a suitable site for agricultural trials. The experimental scientist, in fact, will not be satisfied by an apparently uniform piece of land, but will want to know the previous history of the field (crops cultivated and manures applied), will investigate potential biases (slope, drainage, fertility, etc.), and when satisfied that these elements are not a hindrance, will select a sector of the field far away from any trees that might shade the growing crop, and there begin to measure 
and label plots, randomise the treatments, etc. In the end the experimental field will not be a part of the natural landscape, but a novel setting reshaped by general statistical principles and local agricultural practices. Thus, agricultural institutions have always maintained records - of weather, plant growth, farming practices, etc. - as an essential instrument in their ambition to produce scientific knowledge starting from local data. Farmers engaged in experimentation are not subject to the same constraints, since they are interested only in answering specific questions over their own land.

The field as a site of experimental activity offers also the opportunity to discuss how the geography of agricultural experimentation is subject to the influence of society at large and how the sites of agricultural experiments can become contested spaces. Agricultural experiments are performed not only in secluded and sheltered laboratories, where the general public is rarely admitted, but also in open spaces where controversy can turn bitter and the experimenter's agenda has to come to an accommodation with public concerns and society at large. A notable example is offered, for instance, by GM crop field trials in France. Experimentation with genetically modified crops began in France during the 1980s and, at that point, it raised no protests. However, by the turn of the twenty-first century field trials had become the main issue in the French public debate on genetically modified organisms and several experiments with GM plants were destroyed by protesters. This change in public attitude was "used to consolidate a definition of the GM crops problem as one of socioeconomic choice rather than one of environmental or health risks" (Bonneuil et al. 2008, p. 202). This is just one example of a general feature of agricultural experiments: scientific choices are constantly re-evaluated within the broader framework of the civil society, as suggested also by the Randomised Badger Culling Trial discussed in this issue by Angela Cassidy.

In conclusion, it is apparent that charting the history of agricultural experiments in the twentieth century is a challenging enterprise due to the multiplicity of people, places and activities involved. Yet, engaging with this story yields up its own rewards. Examining the material culture and the experimental practices adopted in the fields and laboratories where agricultural trials take place, offers in fact the opportunity of asking questions whose relevance is not limited to the history of agricultural research alone. As demonstrated by the papers presented in this special issue, agricultural experiments, in fact, touch upon concerns related to human health and nutrition, general methods of experimental research, and policy issues in public life. Agricultural experimentation, therefore, can offer a novel insight into human development, bringing together local and global factors, bridging the demarcation between practical and fundamental research, and uncovering the social and political structures in which farming is embedded.

Acknowledgments The papers in the special issue are derived from talks for a panel on experiments in twentieth-century agricultural science held at the conference of the British Society for the History of Science in St Andrews (3-6 July 2014). Since then they have grown into the more structured papers presented here thanks to the generous support given to the project by the editors of History and Philosophy of the Life Sciences, Staffan Müller-Wille and Sabina Leonelli, and to the dedicated effort of the participants. 


\section{References}

Atkins, P. J. (2000). The pasteurisation of England: The science, culture and health implications of milk processing, 1900-1950. In D. F. Smith \& J. Phillips (Eds.), Food, science, policy and regulation in the twentieth century: International and comparative perspectives (pp. 37-51). London and New York: Routledge.

Bonneuil, C. (2006). Mendelism, plant breeding and experimental cultures: Agriculture and the development of genetics in France. Journal of the History of Biology, 39(2), 281-308.

Bonneuil, C., Joly, P.-B., \& Marris, C. (2008). Disentrenching experiment: The construction of GM-crop field trials as a social problem. Science, Technology \& Human Values, 33(2), 201-229.

Borges, J. L. (1998). Collected fictions (A. Hurley, Trans.). New York: Penguin.

Brassley, P. (1995). Agricultural research in Britain, 1850-1914: Failure, success and development. Annals of Science, 52(5), 465-480.

Burian, R. M. (1997). Exploratory experimentation and the role of histochemical techniques in the work of Jean Brachet, 1938-1952. History and Philosophy of the Life Sciences, 19(1), 27-45.

Charnley, B. (2011). Agricultural science, plant breeding and the emergence of a mendelian system in Britain, 1880-1930. Doctoral Dissertation, University of Leeds.

Clarke, E. (2004). Gilbert, Sir Joseph Henry (1817-1901). Oxford dictionary of national biography (A. E. Johnston, Rev.). Oxford: Oxford University Press.

Cooke, G. W. (Ed.). (1981). Agricultural research 1931-1981. London: Published by the Agricultural Research Council.

Fisher Box, J. (1980). Gosset, Fisher, and the $t$ distribution. The American Statistician, 35(2), 61-66.

Galison, P. (1997). Image \& logic: A material culture of microphysics. Chicago: The Chicago University Press.

Gosset, W. S. (1962). Letters from W. S. Gosset to R. A. Fisher, 1915-1936. Dublin: Printed for private circulation by Arthur Guinness and Sons.

Hacking, I. (1983). Representing and intervening. Cambridge: Cambridge University Press.

Harwood, J. (2005). Technology's dilemma: Agricultural colleges between science and practice in Germany, 1860-1934. Bern: Peter Lang.

Harwood, J. (2006). Introduction to the special issue on biology and agriculture. Journal of the History of Biology, 39(2), 237-239.

Harwood, J. (2012). Europe's green revolution and others since: The rise and fall of peasant-friendly plant breeding. London: Routledge.

Harwood, J. (2015). Did Mendelism transform plant breeding? Genetic theory and breeding practice, 1900-1945. In D. Phillips \& S. Kingsland (Eds.), New perspectives on the history of life sciences and agriculture (pp. 345-369). New York: Springer International Publishing.

Henke, C. R. (2000). Making a place for science: the field trial. Social Studies of Science, 30(4), 483-511.

Kloppenburg, J. R. (1988). First the seed: The political economy of plant biotechnology, 1492-2000. Cambridge: Cambridge University Press.

Kohler, R. E. (2002). Landscapes and labscapes. Chicago: The University of Chicago Press.

Leonelli, S. (2007). Arabidopsis, the botanical Drosophila: From mouse cress to model organism. Endeavour, 31(1), 34-38.

Leonelli, S. (2012). Making sense of data-driven research in the biological and biomedical sciences. Studies in History and Philosophy of Biological and Biomedical Sciences, 43(1), 1-3.

Livingstone, D. N. (2003). Putting science in its place. Geographies of scientific knowledge. Chicago: The University of Chicago Press.

Maat, H. (2011). The history and future of agricultural experiments. NJAS Wageningen Journal of the Life Sciences, 57(3-4), 187-195.

Mead, R., Curnow, R. N., \& Hasted, A. M. (2002). Statistical methods in agriculture and experimental biology (3rd ed.). Boca Raton: CRC Press.

Müller-Wille, S. (2005). Early Mendelism and the subversion of taxonomy: Epistemological obstacles as institutions. Studies in History and Philosophy of Biological and Biomedical Sciences, 36(3), 465-487.

Müller-Wille, S. (2007). Hybrids, pure cultures, and pure lines: From nineteenth-century biology to twentieth-century genetics. Studies in History and Philosophy of Biological and Biomedical Sciences, 38, 796-806. 
Opitz, D. L. (2013). "A triumph of brains over brute": Women and science at the Horticultural College, Swanley, 1890-1910. Isis, 104(1), 30-62.

Palladino, P. (1993). Between craft and science: Plant breeding, Mendelian theory, and the universities in Britain, 1900-1920. Technology and Culture, 34, 300-323.

Palladino, P. (1994). Wizards and devotees: On the Mendelian theory of inheritance and the professionalization of agricultural science in Great Britain and the United States, 1880-1930. History of Science, 32, 409-444.

Paul, D. B., \& Kimmelman, B. (1988). Mendel in America: Theory and practice, 1900-1917. In R. Rainger, et al. (Eds.), The American development of biology (pp. 281-310). Philadelphia: University of Pennsylvania Press.

Phillips, D., \& Kingsland, S. (Eds.). (2015). New perspectives on the history of life sciences and agriculture. Switzerland: Springer International Publishing.

Rae, R. (1955). The work of the national agricultural advisory service. Annals of Applied Biology, 42, 260-271.

Rheinberger, H.-J. (1997). Toward a history of epistemic things: Synthesizing proteins in the test tube. Stanford: Stanford University Press.

Richards, P. (1989). Farmers also experiment: A neglected intellectual resource in African science. Discovery and Innovation, 1, 19-25.

Richmond, M. L. (2007). Opportunities for women in early genetics. Nature Reviews Genetics, 8, 897-902.

Rothamsted Experimental Station. (1921). Report 1918-20 with the supplement to the 'Guide to Experimental Plots'. Harpenden: Printed by D. J. Jeffery.

Saraiva, T. (2010). Fascist labscapes: Geneticists, wheat, and the landscapes of fascism in Italy and Portugal. Historical Studies in the Natural Sciences, 40(4), 457-498.

Schwarz, A. (2014). Experiments in practice. London: Pickering \& Chatto.

Scott, J. C. (1998). Seeing like a state: How certain schemes to improve the human condition have failed. New Heaven: Yale University Press.

Steinle, F. (2002). Experiments in history and philosophy of science. Perspectives on Science, 10(4), 408-432.

Wieland, T. (2006). Scientific theory and agricultural practice: Plant breeding in Germany from the late 19th to the early 20th century. Journal of the History of Biology, 39(2), 309-343.

Woods, A. (2004). A manufactured plague: The history of foot-and-mouth disease in Britain. London: Earthscan. 